\title{
The Performance of Coconut Shell-based Activated Carbon (CSAC) in Treating Drinking Water
}

\author{
W. Chali, and I. Yakub
}

\begin{abstract}
The demand and market growth of activated carbon (AC) in drinking water treatment have been increasing over the recent years. This is because of the better properties and relatively lower cost of AC compared to inorganic adsorbents like ceramics. However, there have been limited studies on the effects of AC preparation including type of cleansing agent on the adsorption of metal and the turbidity of treated tap water. Therefore, this research investigated the effect of types of cleansing agent and sorbent dosage on turbidity reduction and metal removal in drinking water treatment. The analysis showed that $200 \mathrm{~g}$ dosage of $\mathrm{AC}$ that has been cleansed with $\mathrm{FeCl}_{3}$ has the turbidity and metal removal improved the most. For aesthetic value of drinking water though, filtration by using $\mathrm{AC}$ cleansed with $\mathrm{KOH}$ gave better taste and increasing the sorbent dosage up to $300 \mathrm{~g}$ increased this performance.
\end{abstract}

Keywords: activated carbon, coconut shell, cleansing agents, carbon dosage, drinking water

\section{INTRODUCTION}

$\mathrm{S}$ AFE drinking water is defined as the water that does not represent any significant risk to health over a lifetime and is suitable for all common domestic purposes, including personal hygiene [1]. It should contain no impurity that would offend the senses of sight, taste, or smell which reflect its aesthetic value [2]. In some countries, water filter is used to treat water before drinking even though the water is potable standard because of the changing aesthetic value of water flowing in the distribution pipes.

There are many types of water filter, and activated carbon is one of the materials used to remove most of these problems where contaminants are adsorbed when water flows through the voids in the bed of this material [3]. Activated carbon is a porous and black carbonaceous solid processed in the absence of oxygen in order to increase the number of pores [4].

When water passes over the activated carbon, any chemicals or contaminants in the water are bonded at a molecular level to the carbon, effectively removing them from the water [5]. The materials used in the construction of drinking water treatment and distribution systems must not affect negatively the quality of water that is supplied to the customer [6]. In this present study, the post-preparation and dosage of activated carbon used for drinking water treatment were investigated for their effects on the treated water such as turbidity, metal content and aesthetic value of the water. Thus, it verified the suitability of coconut shell-based activated carbon for safe use in drinking water treatment.

The parameters that have been chosen in this scope of studies as listed in Malaysian National Drinking Water Standard are turbidity from Group 1, iron (Fe) from Group 2 and zinc $(\mathrm{Zn})$ from Group 3. Since the commercial AC used in this research had been prepared in a bulk amount, further process needs to be done before it can be used in water treatment filter. Three types of cleansing agents were used in this study were Potassium Hydroxide ( $\mathrm{KOH})$, Iron (III) Chloride $\left(\mathrm{FeCl}_{3}\right)$ and $\mathrm{Zinc}$ Chloride $\left(\mathrm{ZnCl}_{2}\right)$ which are usually used for impregnation of the raw material before carbonization of activated carbon. For the dosage of sorbent, $100 \mathrm{~g}, 200 \mathrm{~g}$ and $300 \mathrm{~g}$ were used where $300 \mathrm{~g}$ is the maximum capacity of the AC in the filter cartridge.

\section{MATERIALS AND METHODS}

\subsection{Sample Preparation}

A sample of tap water which acted as control water was collected into a beaker after it passed through the column with a continuous flow. The tap was flushed until the temperature of the flowing water does not vary by more than $1^{\circ} \mathrm{C}$ over a period of $1 \mathrm{~min}$ and did not exceed $25^{\circ} \mathrm{C}$. Preparation of control water was carried out on the same day of assessment day.

W. Chali was a student of Chemical Engineering \& Energy Sustainability Dept., Faculty of Engineering, University Malaysia Sarawak (UNIMAS) (corresponding author, Tel: +60148725946; e-mail: alynahmail@gmail.com).

I. Yakub is a lecturer of Chemical Engineering \& Energy Sustainability Dept, Faculty of Engineering, Universiti Malaysia Sarawak (UNIMAS). (corresponding author, Tel: +60 82583338 (direct line); e-mail: yibrahim@feng.unimas.my). 
The virgin granular activated carbon (GAC) was rinsed for about 10 minutes with tap water to remove any fine particles from their surface and then heated in the oven for about 2 hours for hygienic purposes. Different amount of GAC to be filled into filter cartridge were $100 \mathrm{~g}, 200 \mathrm{~g}$ and $300 \mathrm{~g}$. For post-preparation purposes, GAC was immersed in Zinc Chloride (ZnCI $)$, Potassium Hydroxide $(\mathrm{KOH})$ and Ferric Chloride $\left(\mathrm{FeCI}_{3}\right)$ solutions at 1:10 ratio before rinsed with distilled water and ovendried. All chemicals used were analytical grade and purchased from Merck (Germany). Table 1 shows the experimental matrix of this experiment.

Table 1 Experimental matrix

\begin{tabular}{cccc}
\hline Experiment & Manipulated variable & Fixed variable & $\begin{array}{c}\text { Labeling of the activated } \\
\text { carbons }\end{array}$ \\
\hline Effect of cleansing agent & $\begin{array}{c}\text { Normal, } \mathrm{KOH}, \mathrm{FeCl} \\
\mathrm{ZnCl}_{2}\end{array}$ & $\begin{array}{c}200 \mathrm{~g} \\
(\mathrm{Dosage})\end{array}$ & $\begin{array}{c}\mathrm{AC}(2), \mathrm{ACK}(2), \\
\mathrm{ACFe}(2), \mathrm{ACZn}(2)\end{array}$ \\
Effect of sorbent dosage & $100 \mathrm{~g}, 200 \mathrm{~g}, 300 \mathrm{~g}$ & $\begin{array}{c}\mathrm{FeCl} \\
\text { (Cleansing agent) }\end{array}$ & $\mathrm{ACFe}(1), \mathrm{ACFe}(2), \mathrm{ACFe}(3)$ \\
& & \\
\hline
\end{tabular}

\subsection{Experimental Setup \& Method}

An AC water filter consists of a filter cartridge that may contain AC powder, granules, solid block and paper membrane or wound spool made of carbon-impregnated cotton cord or foam [7]. In this experiment, the AC used was in granular form ranging from 0.59 to $2.38 \mathrm{~mm}$ particle size and the type of filtration used was pour-through-filter which is the simplest and portable since no installation was required. The filter was held over a container and tap water was poured in at $30 \mathrm{~mL} / \mathrm{s}$.

Water samples were collected from the filter effluent to evaluate the parameters to be studied. Three parallel samples, each with a volume $500 \mathrm{~mL}$, were analysed by using different assessment method depending on the parameters to be checked.

For odour and taste, three panelists that passed the panelists requirement test assessed the treated test water and compared with control water to detect any presence of discernible taste. Each panelist was instructed to take into the mouth whatever volume of water was comfortable and to hold it in the mouth for several seconds before discharging it without swallowing for taste assessment. Besides, turbidity meter was used to determine increase or decrease in turbidity of the water sample as compared to control water. In addition, inorganic substances extraction was determined by using fire atomic absorption spectrophotometry (FAAS).

\section{RESUlTS AND DisCUSSION}

\subsection{The Effect of Types of Cleansing Agent}

Figure 1 shows the relationship between the Nephelometric Turbidity Unit (NTU) reductions and AC cleansed with different types of cleansing agent. It can be observed that all AC cleansed using the cleansing agents reduced the turbidity of water. The NTU reduction is increasing in the order of $\mathrm{AC}(2)<\mathrm{ACK}(2)<\mathrm{ACZn}(2)<\mathrm{ACFe}(2)$. The turbidity reduced as more particles in the water were being adsorbed by the activated carbon. This showed that the adsorption of particles on the surface of $\mathrm{ACFe}(2)$ was more than using $\mathrm{AC}(2)$.

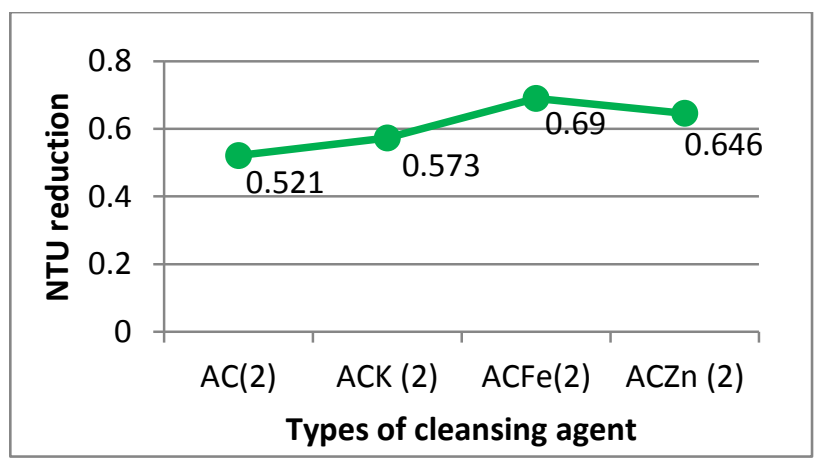

Figure 1 NTU reduction by using different type of cleansing agents.

Adsorption occurs when the attractive forces at the carbon surface overcome the attractive forces of the liquid. The reason is when water passes over the AC, any chemicals or contaminants in the water are bonded at molecular level to the carbon, thus effectively remove them from water [3]. The result is also expected because $\mathrm{FeCl}_{3}$ is a good coagulant agent [8].

Figure 2 shows the changes in metals content $(\mathrm{Zn}$ and $\mathrm{Fe}$ ) of water when treated using AC cleansed by different cleansing agents. The graph shows that $\mathrm{AC}(2), \operatorname{ACK}(2)$ and $\mathrm{ACFe}(2)$ resulted positive changes which reflect that the ability of reducing the $\mathrm{Zn}$ content can be achieved by AC cleansed using any of the chemicals except $\mathrm{ZnCl}_{2}$. This is because $\mathrm{ACZn}(2)$ gave negative change in $\mathrm{Zn}$ content which means the $\mathrm{Zn}$ content was increased after the treatment. This indicated that there was leach of $\mathrm{Zn}$ from $\mathrm{ACZn}(2)$ which was due to inadequate removal of $\mathrm{ZnCl}_{2}$ residues during cleansing process [9]. As the GAC (before cleansed) used did not contain traces amount of $\mathrm{Zn}$, it was evident that the $\mathrm{Zn}$ ion leached was from the AC 
(after cleansed). Therefore, it is accepted that $\mathrm{AC}(2), \mathrm{ACK}(2)$ and $\mathrm{ACFe}(2)$ were good in removing $\mathrm{Zn}$.

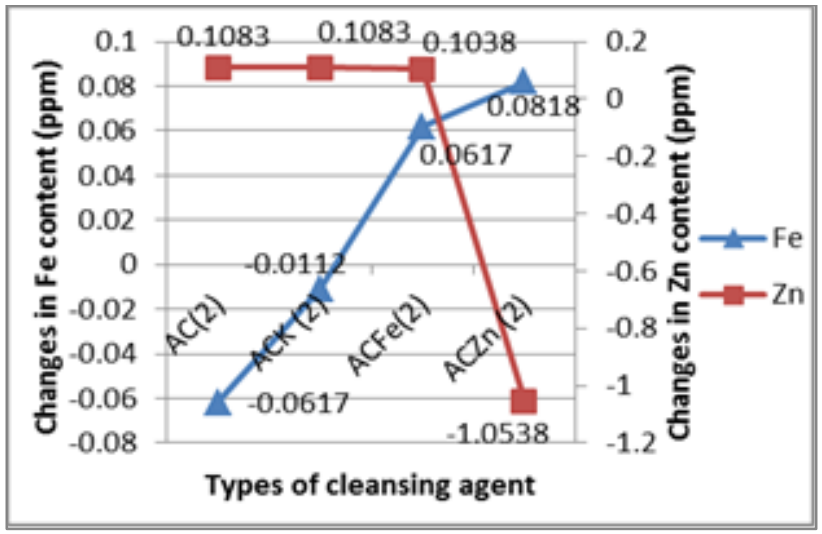

Figure 2 Changes in metals content by using different types of cleansing agent

For Fe content, only $\mathrm{ACFe}(2)$ and $\mathrm{ACZn}(2)$ could reduce the content of Fe in water with more Fe been removed by using $\mathrm{ACZn}(2)$. Fe from the tap water displaced the $\mathrm{Zn}$ adsorbed by AC during cleansing process with $\mathrm{ZnCl}_{2}$. That was because $\mathrm{Fe}$ had higher affinity to be adsorbed on the surface of $\operatorname{ACZn}(2)$ than on $A C F e(2)$ [10]. This could also be related to the leach of $\mathrm{Zn}$ from $\mathrm{ACZn}(2)$ from previous discussion of $\mathrm{Zn}$ content where the $\mathrm{Zn}$ adsorbed on $\mathrm{ACZn}(2)$ was displaced by Fe from water.

Both $\mathrm{AC}(2)$ and $\mathrm{ACK}(2)$ gave negative changes of Fe content which showed that Fe was leached from the AC. Since the $\mathrm{AC}$ used contained $\mathrm{Fe}$, the leached Fe from both $\mathrm{AC}(2)$ and $\operatorname{ACK}(2)$ might be due to inadequate removal of Fe from the surface of AC during cleansing process. The larger amount of Fe leaching from $\mathrm{AC}(2)$ as compared to Fe leaching from $\mathrm{ACK}(2)$ showed that the bonding of $\mathrm{Fe}$ with the $\mathrm{AC}$ before treated using $\mathrm{KOH}$ was initially weak and cleansing the AC with $\mathrm{KOH}$ had removed the Fe which reduced Fe content in the AC. Hence, it could be proven that ACZn(2) adsorbed more Fe than by using $\mathrm{AC}(2), \operatorname{ACK}(2)$ and $\operatorname{ACFe}(2)$.

The optimal cleansing agent could be found by relating types of cleansing agent used with changes in Zn content and NTU reduction in the water as shown in Figure 3. The reason of comparing with changes in $\mathrm{Zn}$ content instead of changes in Fe content was that the amount of $\mathrm{Zn}$ reduced by the $\mathrm{AC}$ was more than reduction of $\mathrm{Fe}$ when the same type of $\mathrm{AC}$ was used. From Figure 3, since the $\mathrm{Zn}$ content from all three AC gave the same amount of reduction, the comparison was narrowed down to the types of cleansing agent that could reduce the turbidity the most. The most preferable types of cleansing agent increased in the manner of $\mathrm{AC}(2)<\mathrm{ACK}(2)<\mathrm{ACFe}(2)$. Thus, it could be verified that $\mathrm{FeCl} 3$ was the optimal cleansing agent which could remove both turbidity and $\mathrm{Zn}$ content.

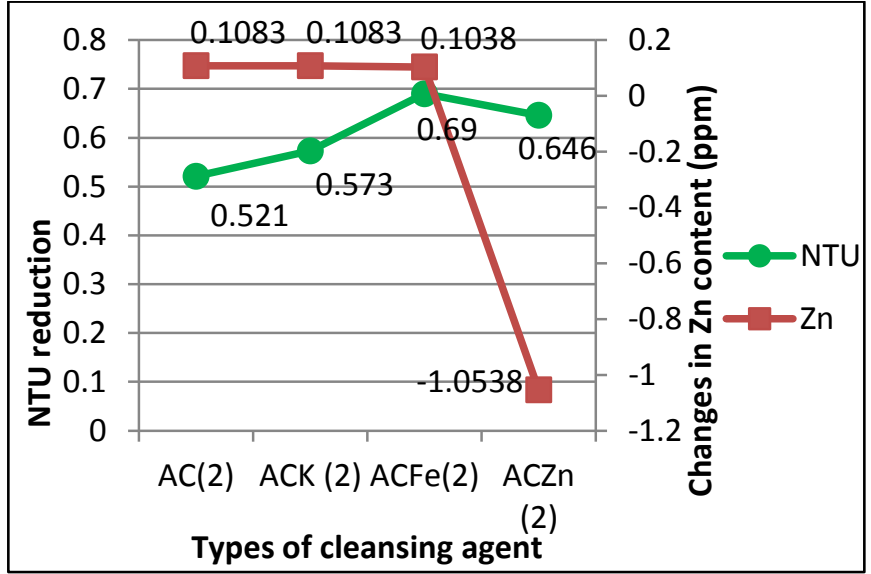

Figure 3 NTU reduction and changes in Zn content by using different types of cleansing agent

\subsection{The Effect of AC Dosage}

Figure 4 gives the relationship between NTU reductions with different dosage of AC. The turbidity reduction increased in the manner of $\mathrm{ACFe}(1)<\mathrm{ACFe}(3)<\mathrm{ACFe}(2)$. It showed that $\mathrm{ACFe}(2)$ reduced the turbidity the most because it had more exposed active sites or higher surface area for adsorption of the particles in the water to take place as compared to ACFe(1). Hence, increase in dosage of activated carbon increased the surface area and active site for adsorption process to take place [11]. Furthermore, the turbidity reduction was also higher compared to $\mathrm{ACFe}(3)$. This indicated that increase in dosage of $\mathrm{AC}$ after $200 \mathrm{~g}$ lowered the reduction of turbidity. This might be due to increase in attrition of particles that has resulted more fine powders at higher dosage. Therefore, it could be accepted that $200 \mathrm{~g}$ was the best dosage for turbidity removal for 30 $\mathrm{mL} / \mathrm{s}$ of flow rate 
UNIMAS e-Journal of Civil Engineering: Volume 4, Issue 3

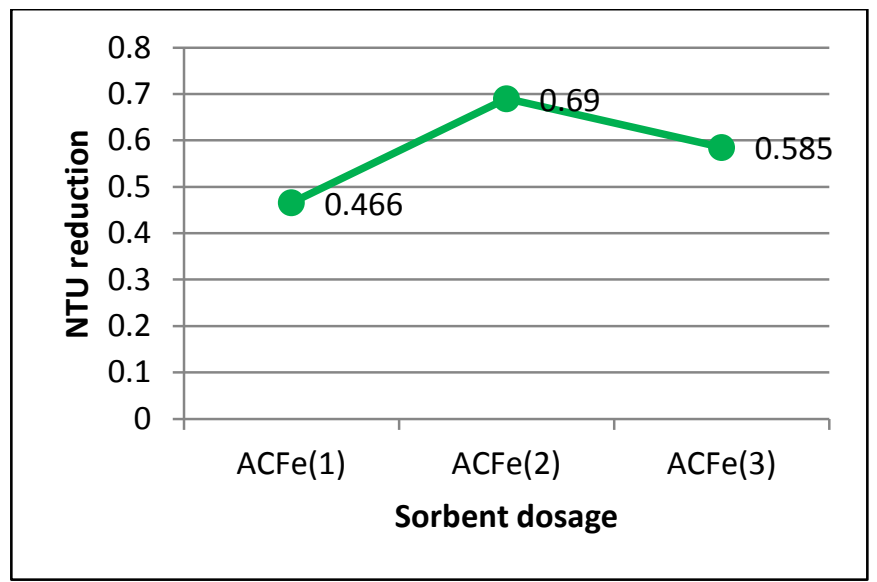

Figure 4 NTU reduction by using different dosage of AC

Figure 5 shows the changes in metals content ( $\mathrm{Zn}$ and $\mathrm{Fe}$ ) of water when treated using different dosage of AC. For $\mathrm{Zn}$ content, it indicated that all dosage of $\mathrm{AC}$ did reduce the $\mathrm{Zn}$. The increasing removal of $\mathrm{Zn}$ was in the order of $\mathrm{ACFe}(1)<\mathrm{ACFe}(2)<\mathrm{ACFe}(3)$. This was because $\mathrm{ACFe}(3)$ had more contact surface area as compared to $\mathrm{ACFe}(1)$. Hence, more $\mathrm{Zn}$ could be adsorbed. The immense surface area of AC formed during activation process gave AC an extremely adsorptive property [12]. Therefore, it could be said that increase in the dosage of $\mathrm{AC}$ also increased in the surface contact area for metal adsorption process to take place.

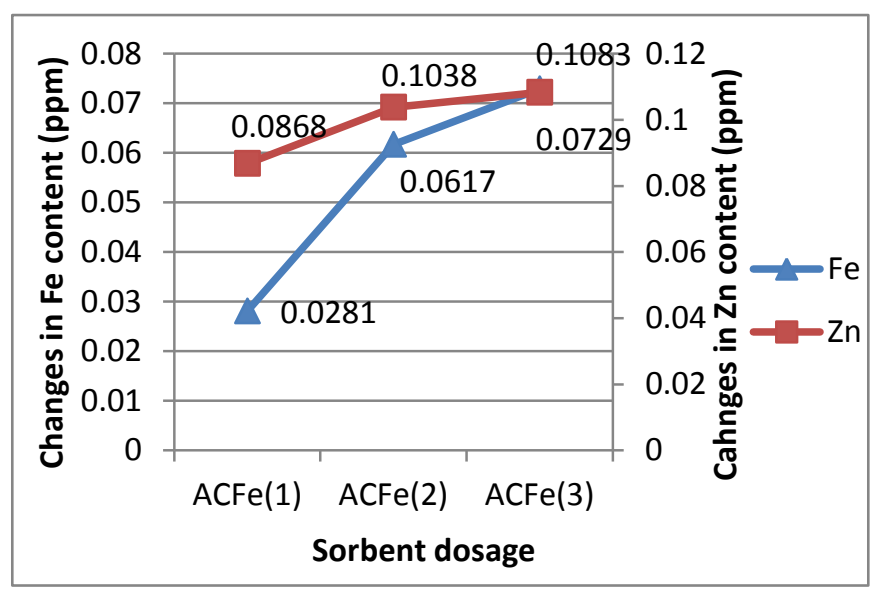

Figure 5 Changes in metals content by using different dosage of AC.

The increasing Fe removal was in increasing order of $\mathrm{ACFe}(1)<\mathrm{ACFe}(2)<\mathrm{ACFe}(3)$. The result was similar which showed that $\mathrm{ACFe}(3)$ could reduce $\mathrm{Fe}$ content the most. The difference was that, increasing dosage of sorbent gave better and constant removal of Fe. Since ACFe(3) showed the most reduction of metal, it could be proven that ACFe(3) was the best to be used for metal removal because it could remove both $\mathrm{Zn}$ and Fe.

The optimal sorbent dosage was found by relating sorbent dosage with the amount of Fe removed and NTU reduction of the water (Figure 6.). The reason for comparing NTU reduction with Fe removal instead of $\mathrm{Zn}$ removal was that the Fe removal for different dosage gave constant reduction of $\mathrm{Fe}$ as compared to reduction of $\mathrm{Zn}$ using different dosage of AC. For $\mathrm{ACFe}(1)$, it did reduce the turbidity and $\mathrm{Fe}$ content. However, the reduction of both turbidity and $\mathrm{Fe}$ was the lowest value as compared to $\mathrm{ACFe}(2)$ and $\mathrm{ACFe}(3)$. Therefore, $\mathrm{ACFe}(1)$ could not be considered as the optimal sorbent dosage. Meanwhile, both $\mathrm{ACFe}(2)$ and $\mathrm{ACFe}(3)$ reduced the turbidity and Fe. In terms of turbidity, $\mathrm{ACFe}(2)$ could reduce more NTU as compared to $\mathrm{ACFe}(3)$, while in terms of Fe removal, $\mathrm{ACFe}(3)$ could remove more $\mathrm{Fe}$ as compared to $\mathrm{ACFe}(2)$. Based on the graph, ACFe(2) gave more consistency in the reduction of both NTU and Fe. Therefore, ACFe(2) could be regarded as the optimal sorbent dosage. 


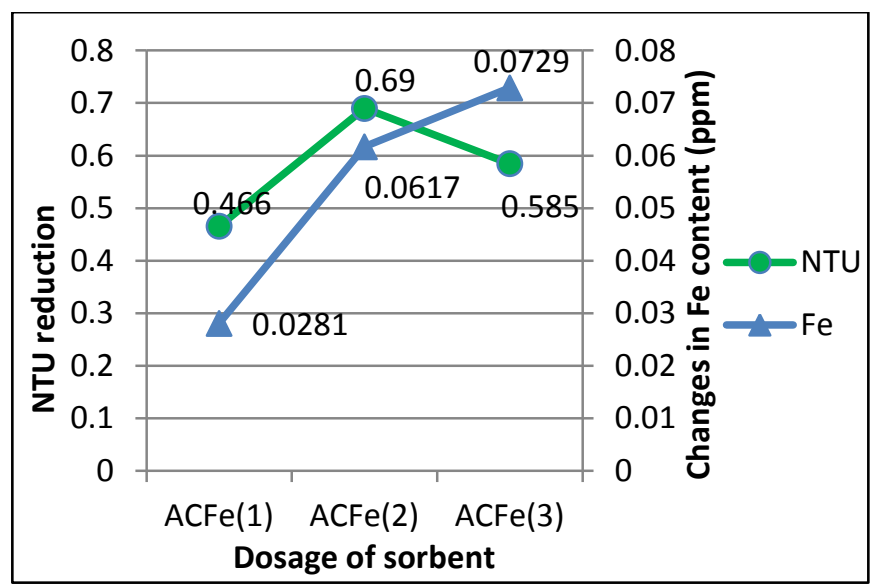

Figure 6 NTU reduction and changes in Fe content with by using different dosage of AC

\subsection{The Aesthetic Value of the Drinking Water}

All water samples had passed the odor test where no substantial color and odor can be detected by any of the panelists. The discussion is now focused on taste test of water samples. Table 2 shows the aesthetic values of drinking water as evaluated by different panels for cleansing agent. The range of their preference was valued from 1 to 5 which were from good to very good as compared to control.

Table 2 The preference of panels for different types of cleansing agent.

\begin{tabular}{cccc}
\hline Sample & Panel 1 & Panel 2 & Panel 3 \\
\hline Control & 1 & 1 & 1 \\
AC(2) & 2 & 2 & 2 \\
ACK (2) & 5 & 5 & 5 \\
ACFe(2) & 3 & 4 & 4 \\
ACZn(2) & 4 & 3 & 3 \\
\hline
\end{tabular}

Two out of three panelists stated that their preference in terms of cleansing agent was in increasing order of $\mathrm{AC}(2)<\mathrm{ACFe}(2)<\mathrm{ACZn}(2)<\mathrm{ACK}(2)$. However, all of them agreed that the taste of water treated using $\mathrm{ACK}(2)$ had superior taste. Figure 7 shows the rating of panel preference as evaluated for water treated using three types of cleansing agent and the turbidity of the treated water. Turbidity of water treated using $\operatorname{ACK}(2), \operatorname{ACFe}(2)$, and $\operatorname{ACZn}(2)$ were $0.676,0.559,0.603$ NTU respectively while AC(2) produced water of 1.08 NTU. This shows AC(2) did not reduce much turbidity as compared to control that had turbidity of 1.249 NTU. However, the water filtered with $\operatorname{ACK}(2)$ was preferred the most because of the alkalinity of the treated water. $\mathrm{KOH}$ was a basic solution meanwhile $\mathrm{FeCl}_{3}$ and $\mathrm{ZnCl}_{2}$ were Lewis acid. Thus, it could be accepted that the $\mathrm{pH}$ of the water could affect the aesthetic value of the drinking water.

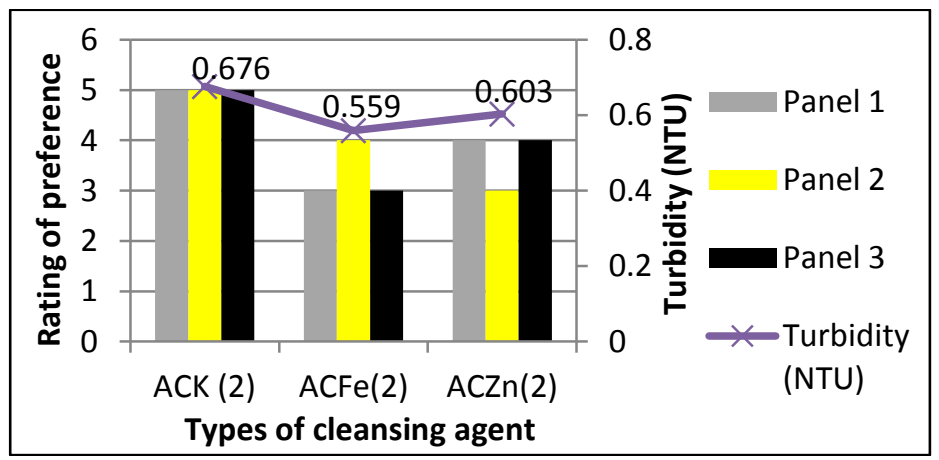

Figure 7 Rating of preference based on the turbidity of water with different types of cleansing agent used

Table 3 shows the aesthetic values of drinking water as evaluated by different panelists for different sorbent dosage. The range of their preference was from 1 to 3 which were ranged from good to very good. Two out of three panelists stated that their preference on the taste of water increased as the dosage of sorbent increased. Their preference increased in the increasing manner of $\mathrm{ACFe}(1)<\mathrm{ACFe}(2)<\mathrm{ACFe}(3)$. 
UNIMAS e-Journal of Civil Engineering: Volume 4, Issue 3

Table 3 The preference of panels for different dosage of activated carbon.

\begin{tabular}{cccc}
\hline Sample & Panel 1 & Panel 2 & Panel 3 \\
\hline $\mathrm{ACFe}(1)$ & 3 & 1 & 1 \\
$\mathrm{ACFe}(2)$ & 2 & 2 & 2 \\
$\mathrm{ACFe}(3)$ & 1 & 3 & 3 \\
\hline
\end{tabular}

From Figure 8, the metal content for Fe in the water was decreasing in the manner of $\mathrm{ACFe}(1)<\mathrm{ACFe}(2)<\mathrm{ACFE}(3)$. This indicates that the more dosage of sorbent, the more Fe metals could be removed and the better the taste of the water. Therefore, water filtered with sorbent dosage of $300 \mathrm{~g}$ was the most preferable.

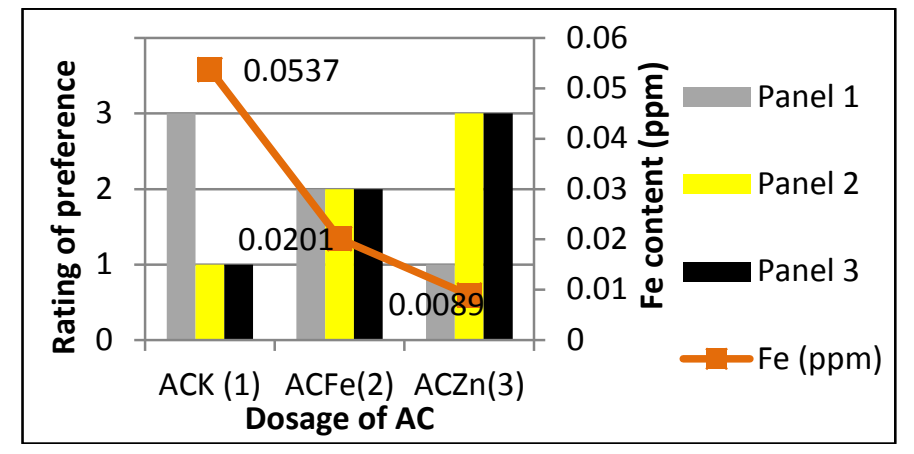

Figure 8 Rating of preference based on the Fe content with sorbent dosage

\section{CONCLUSION}

The performance of CSAC in water filter has been studied focusing on the effects of cleansing agents and carbon dosage on the turbidity and metal content reduction as well as aesthetic quality of drinking water. It has been found that $\mathrm{FeCl}_{3} \mathrm{was}$ the best cleansing agent to reduce turbidity and metal content. In addition, increasing amount of carbon dosage more than $200 \mathrm{~g}$ for $30 \mathrm{~mL} / \mathrm{s}$ water flow rate would not increase the ability of the CSAC to reduce turbidity due to the attrition rate but it could reduce further metal content for total surface area has been increased. For aesthetic value of water, KOH was the most preferred cleansing agent to be used in post-treatment of CSAC because of the improved taste besides the conserved drinking water characteristics that are odorless and colorless. Increasing carbon dosage in the filter could improve the aesthetic quality of the water due to the increased ability of reducing metal content. It can be concluded that the performance of CSAC can be increased by using suitable cleansing agent and optimal carbon dosage in the filter. Further studies are required to validate the safety of such improvement especially when CSAC is to be used in bulk.

\section{ACKNOWLEDGMENT}

This research work reported in this paper has been funded by the Ministry of Higher Education Malaysia under the project RAGS/C(7)/940/2012(41). Besides, the authors would like to acknowledge Norsuzailina Mohamed Sutan for proof-reading this article.

\section{REFERENCES}

[1] World Health Organization. (2012). Retrieved October 2, 2012, from Guidelines for Drinking Water Quality: http://www.who.int/water_sanitation_health/dwq/guidelines/en/.

[2] Hunter, W. J. (2008). Chapter 19. Remediation of Drinking Water for Rural Population. University of Nebraska - Lincoln, 597-621.

[3] Parsons, S. A., \& Jefferson, B. (2006). Activated Carbon. In Introduction to Potable Water Treatment Processes (pp. 116-122). Oxford: Blackwell Publishing Ltd.

[4] Serio, M. A., \& Chen, Y. (2001). Pyroliysis Processing of Mixed Solid Waste Streams. 466-474.

[5] Health Canada. (2008, August 28). Water Treatment Device. Retrieved October 27, 2012, from http://www.hc-sc.gc.ca/ewh-semt/pubs/watereau/devices-dispositifs-eng.php.

[6] Baron, J. (2006). Chapter 4: Materials in contact with drinking water. In P. Quevauviller, \& K. C. Thompson, Analytical Methods for Drinking Water: Advance in Sampling and Analysis (p. 116). Chicester: John Wiley \& Sons Ltd.

[7] Zhang, T. J. (2009). Application and development of activated carbon for potable water treatment in China. Biomass Chemical Engineering, 54-59.

[8] Aygun, A. \& Yilmaz, T. (2010). Improvement of Coagulation-Flocculation Process for Treatment of Detergent Wastewaters Using Coagulant Aids. International Journal of Chemical and Environmental Engineering Vol. 1(2), 97-101.

[9] Jeyaseelan, S., \& Chen, X. G. (2000). Study of leaching and adsorption of heavy metals by the activated carbon derived from sewage sludge. Singapore: Nanyang Technological University.

[10] Cookson, J. (1978). Adsoprtion Mechanism: the chemistry of organic adsorption of Activated Carbon. In Carbon Adsorption Handbook (pp. 241-280) Ann Arbor Air Publication.

[11] Pohan, A. (2010). Treatment of Polluted Water (River) by Using Activated Carbon from Coir Pith. University Malaysia Pahang.

[12] Su, W., Zhou, L., \& Zhou, Y. (2003). Preparation of Microporous Activated Carbon from Coconut Shell without Activating Agent. Elsevier Science Ltd., 861-863. 